\title{
La educación: clave para el futuro de la conservación-restauración del patrimonio
}

\author{
Blanca Flor Herrero Morán | doctora por la Universidad de Salamanca \\ URL de la contribución <www.iaph.es/revistaph/index.php/revistaph/article/view/3536>
}

La educación es un proceso social que alude no sólo a la transmisión de la cultura sino también al desarrollo personal y a la actividad consciente por la que el ser humano trata de explicitar y desenvolver sus competencias con eficiencia y responsabilidad dentro de la sociedad.

Aunque tanto enseñar cómo educar son dos verbos transitivos (se enseña o educa algo), ambas acciones tienen una serie de particularidades que las distinguen. Una de las fórmulas que más claramente evidencia las diferencias, más que notables, que guardan ambos términos es partir del significado etimológico de cada palabra.

Por un lado, enseñar (del latín insignare) hace referencia a señalar, indicar o mostrar; y, por el otro, educar (del latín educare) alude a la capacidad de dirigir, encaminar o doctrinar. Así pues, el término enseñar se relaciona con la instrucción y el amaestramiento mientras que el de educar con la conducción y el acompañamiento.

El futuro de la conservación-restauración del patrimonio está ligado con la educación ya que la educación es clave para salvaguardar y valorar el patrimonio. La educación de la sociedad favorece que los diferentes procesos relacionados con el patrimonio se desarrollen y pongan en práctica de tal manera que para salvaguardar y legar el patrimonio es necesario conocerlo, cuidarlo, protegerlo, conservarlo, restaurarlo y valorarlo.

Para implicar a la sociedad en la conservación-restauración del patrimonio a través de la educación hay que tener en cuenta la existencia de los diferentes ámbitos educativos: formal, no formal e informal.

Dentro de la educación formal o reglada existen distintos niveles en los que se puede educar en el patrimonio que se pueden dividir en dos grandes bloques según del carácter obligatorio de las enseñanzas que se imparten.

En la enseñanza obligatoria, la conservación y restauración del patrimonio puede tratarse de forma trasversal desde distintas áreas o materias como ciencias sociales, ciencias naturales, historia, historia del arte, lengua, ética, inglés, física y química, biología y geología o tecnología. Es más, la conservación y restauración del patrimonio permite el desarrollo de las competencias básicas pues el tema puede ser abordado y tratado empleando diversas metodologías didácticas que favorezcan la competencia en comunicación lingüística, la competencia matemática, la competencia en el conocimiento y la interacción con el mundo físico, la competencia digital, la competencia social y ciudadana, la competencia cultural y artística, la competencia para aprender a aprender, y la autonomía e iniciativa personal.

En la enseñanza pos-obligatoria se desarrolla la competencia básica para la intervención en bienes culturales, pero la dificultad radica en establecer el nivel académico (ciclos formativos, formación profesional, carreras universitarias, máster, doctorados...) en el que impartir los conocimientos y la formación específica necesarios para llevar a cabo las tareas relacionadas con la conservación-restauración del patrimonio. A su vez, la ausencia de una única titulación y la existencia de varias instituciones educativas que imparten diversas especialidades y títulos de conservación y restauración de bienes culturales, dificultan la definición de las convocatorias laborales tanto en prácticas profesionales, ofertas de empleo, bolsas de trabajo como en becas y oposiciones.

De forma genérica, las disciplinas que configuran la formación de un conservador-restaurador están relacionadas 
a debate El futuro de la conservación-restauración de bienes culturales | coordina Pilar Aguilar Solves

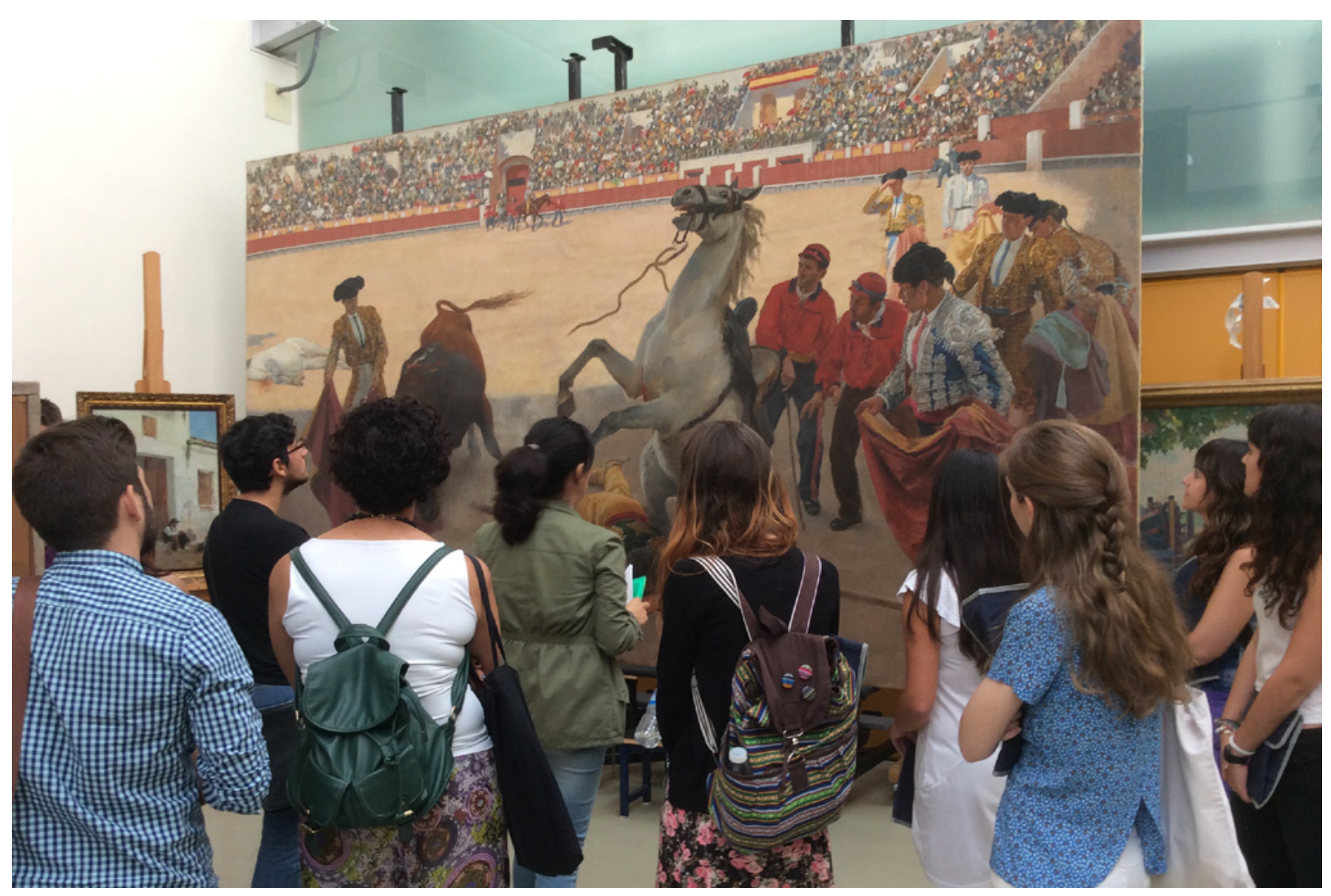

El futuro de la conservación-restauración está ligado a la educación de los distintos agentes que se acercan al patrimonio | foto Fondo Gráfico IAPH

con el conocimiento y documentación de los bienes culturales, y con el estado y los tratamientos de conservación y restauración a los que deben someterse.

No obstante, llama la atención que en las leyes y reglamentos la figura del conservador-restaurador no esté reconocida pues aunque se recoge la necesidad de intervenir en los bienes culturales no se alude al personal competente.
Dentro de la educación no formal, destacan diferentes actividades cotidianas relacionadas con el trabajo y el ocio surgidas a partir de iniciativas desarrolladas por diferentes grupos y colectivos como cursos, congresos o talleres llevados a cabo en academias, asociaciones, fundaciones, bibliotecas, archivos o museos; así como la información generada y transmitida por los diferentes medios de comunicación. La educación no formal es 
a debate El futuro de la conservación-restauración de bienes culturales | coordina Pilar Aguilar Solves

intencionada pero no reglada, y genera diversas actitudes y aptitudes, tanto personales como sociales, basadas en un sistema de valores.

En el caso de la conservación-restauración del patrimonio destaca el asociacionismo generado por los profesionales y especialistas en la materia que denuncian: la falta de una regulación profesional, la carencia de supervisión de las actuaciones realizadas y de control de los efectos provocados que evitarían la mala praxis, y el intrusismo tanto de personas no cualificadas como de aquellos que han participado en escuelas-talleres y/o centros ocupacionales donde se imparten cursos y talleres sobre conservación y restauración en los que las competencias, los objetivos y los estándares no están claramente definidos y delimitados.

Otro aspecto a tener en cuenta es la conveniencia de que todo el personal que tiene relación con los bienes culturales en centros como archivos, bibliotecas o museos tenga una formación adecuada y actualizada sobre conservación y restauración, de acuerdo con su función y responsabilidad.

Por último, la educación informal es aquella que se adquiere a lo largo de la vida de forma no intencionada, no reglada, ni estructurada, en el ámbito cotidiano, doméstico y/o laboral. El fin del aprendizaje informal es el desarrollo personal del ser humano en la vida de forma continua y espontánea.

Tener una buena educación, ser educados y comportarse de forma educada con el patrimonio son aspectos que deben estar presentes en todos los ámbitos educativos.

Para conseguir una educación patrimonial es imprescindible conocer y comprender el patrimonio ya que no se valora aquello a lo que no se encuentra significado, sentido y valor. Concretamente, si existiera una buena educación patrimonial, basada en el conocimiento propio y no impuesto, descenderían los numerosos ataques relacionados con la falta de valoración del patrimonio que se han materializado en hechos como la contaminación visual y la degradación provocada por las pintadas realizadas en distintos bienes culturales.

Lo deseable es partir del conocimiento para llegar al reconocimiento. Se trata de conseguir un buen conocimiento patrimonial que haga referencia tanto a los conceptos como a los modos de hacer y las formas de ser, de tal manera que se favorezca la valoración y el reconocimiento del patrimonio.

Involucrar a la sociedad en la conservación-restauración a través de una buena educación patrimonial permite que, a nivel general, nos ocupemos y preocupemos por el patrimonio, que lo cuidemos y velemos porque no se deteriore, y, a nivel particular, los profesionales y especialistas cualificados y competentes en conservación y restauración se encarguen de emplear protocolos, criterios, pautas, técnicas, medios y mecanismos para que dicha labor se desarrolle con responsabilidad y eficacia. Para ello, es necesaria la regulación de la conservaciónrestauración a nivel profesional y académico ya que permitiría una ordenación específica.

En definitiva, el primer paso para conservar, restaurar, proteger y salvaguardar el patrimonio es conocerlo, comprenderlo y valorarlo, y estos tres aspectos se desarrollan gracias a la educación. 